\title{
Specifying risk management standard for flood risk assessment: a framework for resources allocation
}

\author{
Anastasia Yunika ${ }^{1,2^{*}}$, Matthijs $\mathrm{Kok}^{1}$, and Jacob Gerrit (Jarit)de Gijt ${ }^{1}$ \\ ${ }^{1}$ Hydraulic Structures and Flood Risk Section, Delft University of Technology, Delft, the Netherlands \\ ${ }^{2}$ Civil Engineering Department, Universitas Atma Jaya Yogyakarta, Yogyakarta, Indonesia
}

\begin{abstract}
General risk management standard, e.g. ISO 31000:2009, approaches risk as a coin with a pair of two sides, i.e. the threat and the opportunity. However, it is hardly the case of flood events which mainly come as threats. Despite the contrary, this study explores the potential applicability of the available risk management standards specifically for flood. It then also synthesizes the components to result a framework for allocating resources among various strategies to result the optimum flood risk reduction. In order to review its applicability, the framework is then reviewed using several historic flood risk reduction cases. Its results are qualitatively discussed and summarized including the possible improvement of the framework for further applications.
\end{abstract}

\section{Introduction}

In the daily life terminology, "risk" is commonly perceived as something with harmful outcome or is simply related to more possibility of negative result, shortly, a situation of threat. In general, there is no standard available for risk management in such condition. Different persons faced to a particular circumstance with a certain type and level of risk will make decision or take action regarding that situation differently one from another based on personal preferences, priorities, experiences, and many other aspects. On the other hand, in the economy-related fields, e.g. finance, business, and investment, "risk" is defined more neutrally by considering both the possibility of gain (positive yield) and loss (negative yield). The basic understanding is that there is the probability of difference between the actual and expected returns [1]. In this field, a risk management standard has been developed and at the international level, ISO 31000:2009 is the latest one, in which "risk" is defined as the "effect of uncertainty on objectives" [2].

More specific definition of "risk" used in different areas including flood risk management is the product of occurrence probability and its consequence of hazardous event or phenomenon [3, 4]. The second frequently used formulation of "risk" includes three components, i.e. hazard, exposure, and vulnerability (a.k.a. "Risk Triangle" [5]). Referring to those two definitions, despite its essence as a natural phenomenon, flood is

*Corresponding author: a.yunika@tudelft.nl 
perceived as more of a disturbance, problem, or even disaster at its higher scale due to the impacts of its interaction with humans. This perspective tends to abandon the positive side of flood's essential existence as "an integral part of the hydrologic cycle" [6], e.g. environmental and ecological balancing process, agricultural soil nourishment, water sources recharge, river flushing, as well as topographical formation through erosion and deposition. Consequently, the flood risk reduction measures as part of flood risk assessment and management will less take into account the possibility of gaining the benefit from the flood existence due to the focus merely on minimizing the damage and loss.

This study tries to adapt the concept of general risk management standard, i.e. ISO 31000:2009 specifically for flood risk reduction so that both sides of the coin, i.e. the threat ("loss and detriment") and opportunity ("gain and benefit") can be more proportionally accommodated. By doing so, it is expected that innovative measures in the flood risk reduction can be identified so that resources will be optimally allocated among strategies.

\section{RISK MANAGEMENT}

Despite the semantically self-explaining terminology, ISO 31000:2009 [2] describes "risk management" as shown in Figure 1a in which "risk assessment" is the core part. In addition to it, there are three other components, i.e. "establishing the context", "communication and consultation", "monitoring and review". Similarly, a simplified process described by Jonkman [7] is shown in Figure 1b. On the other hand, a different concept of risk management was presented by Gerrard and Petts [8] as a cyclic process shown in Figure 2 which oppositely considered the "risk perception and communication" as the core component and located it at the center of the cycle while "risk assessment" as one of the outer components. Taking into account the formulation of the process as a well-documented standard, this study opts to adopt the model presented in ISO 31000:2009 in developing the proposed framework that will be discussed further.

\section{RISK ASSESSMENT}

As shown in Figure 1a and 1b, risk assessment is recognized as the core of the risk management process. However, it is well understood that in terms of decision making, there are many different risk assessment approaches. Taking two of them to mention are "quantitative risk assessment" and "comparative risk assessment". The first focuses on the probability quantification of "adverse impact due to exposure" while the second pays attention on "ranking risk issues by their severity for prioritization and justification of resources allocation" [8]. Both approaches will be incorporated in the proposed framework of this study.

\section{PROPOSED FRAMEWORK AND ITS SYNTHESIZATION}

This study emphasizes on the optimum resources allocation among alternatives for optimum flood risk reduction strategy. However, since flood risk reduction as the last phase is inseparable from the preceding phases of risk assessment (Figure 1a), a simplification inappropriately be made more than the four-phase iterative process shown in Figure 3. The first phase of "flood hazard analysis" also covers two subcomponents equal to "establishing the context" and "risk identification" in Figure 1a. They are "mapping of area and its flood risk system" and "flood hazard analysis" itself which are logically and chronologically required. Other proceeding phases of the framework are corresponding to the ones of ISO 31000:2009. The two types risk assessment mentioned earlier in Section 3 are adopted in 
the second and last phases of the framework. The "quantitative risk assessment" is applied to the "flood consequence analysis" while the "comparative risk assessment" is used in the "flood risk reduction".

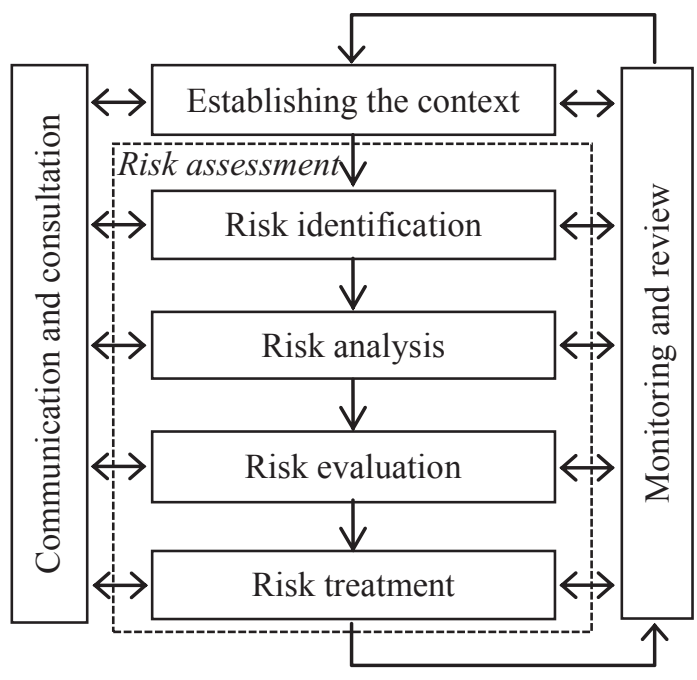

(a)

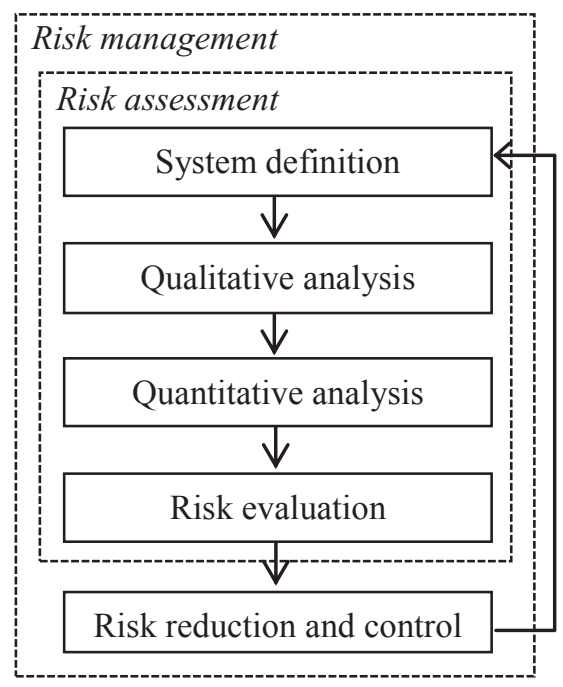

(b)

Fig. 1. Risk management process according to (a) ISO 31000:2009 [2] and (b) Jonkman [7]

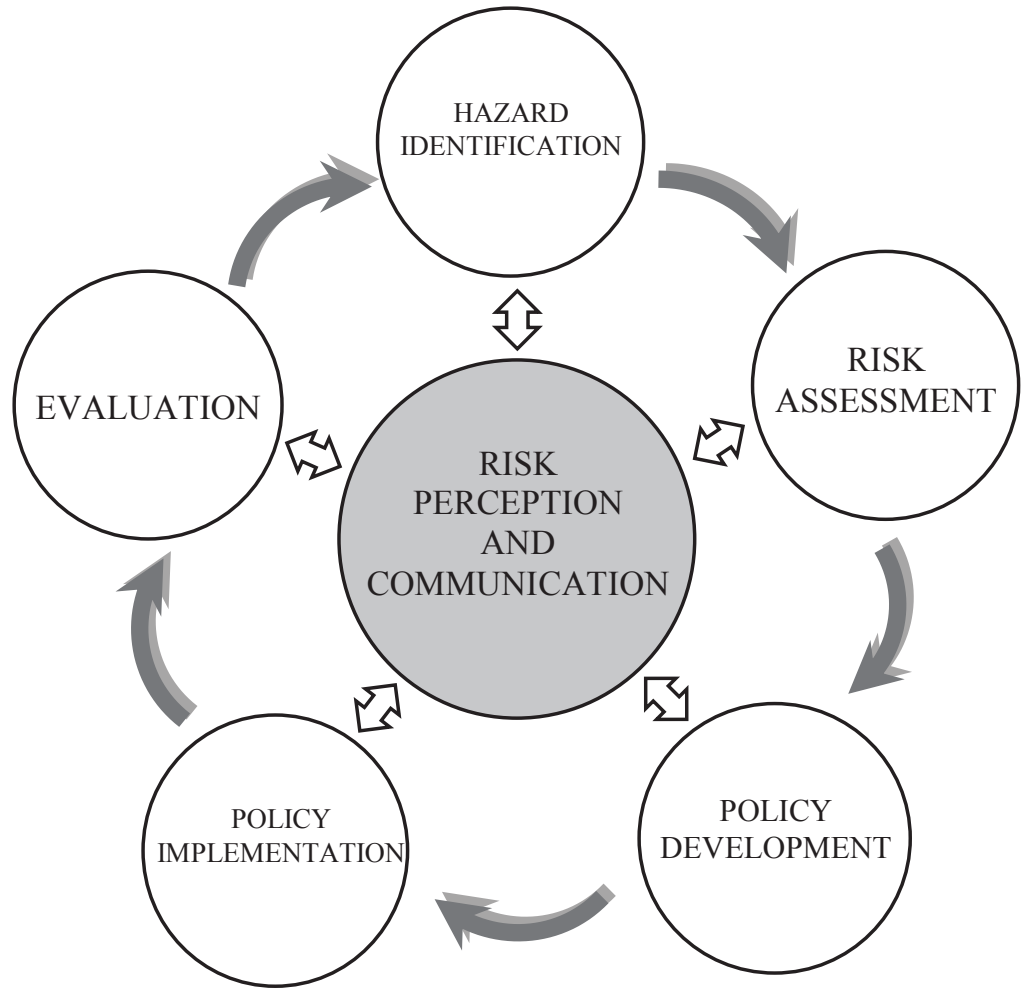

Fig. 2. Risk management cycle according to Gerrard and Petts [8] 


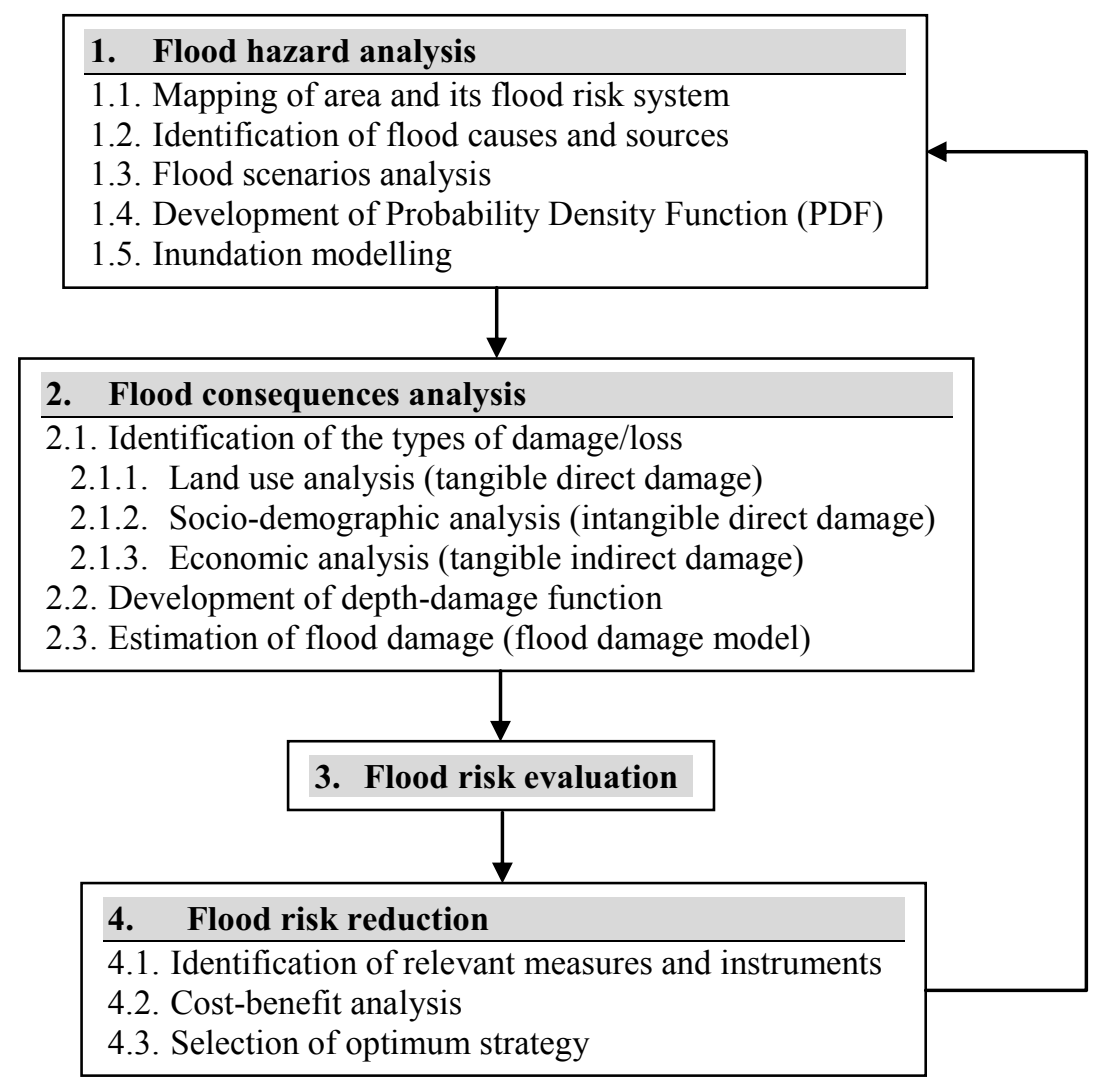

Fig. 3. Proposed framework of this study

In spite of well-recognized concept that risk assessment is a part of risk management, the study by Gerrard and Petts presented an intriguing question of "whether risk assessment as a scientific process can and should be separated from risk management". The idea of either isolation or integration was initiated by the difference between two perspectives in looking at risk assessment, i.e. as "one of the many decision making tools or the decision making process itself". Furthermore, historically, it is also supported by the distinct believes between "logical positivism" and "cultural relativism" upon the "wholly objective" nature of science and scientific process. The earlier supports the exclusion of social and political aspects of decision making since risk assessment is and must be kept objective. The latter argues oppositely since it is impossible. In between the two lies the "scientific proceduralism" which focuses on the process of conducting scientific activities so that "subjective value judgements within technical risk assessment can be acknowledged and dealt with in an appropriate manner". The concept presented in [8] that "science might somehow be conducted isolation and occasionally deliver objective information" is adopted in this study so that the components of risk management in Figure 1a other than the "establishing the context" and risk assessment are excluded from the proposed framework as the first synthesization.

The second synthesization of the framework is conducted upon last phase of Figure 1a. In ISO 31000:2009, "risk treatment" has several possible types, i.e. risk avoidance (i.e. by cancelling the activity, e.g. development, and/or by modifying the condition under which activity is conducted), risk removal (i.e. removing the source of risk), risk modification (i.e. changing the likelihood and/or consequence), risk sharing (i.e. insurance and/or 
outsourcing), and/or risk retention (when the risk level meets the criteria of acceptance). Those types of risk treatment will be used in identification of relevant alternatives of flood risk reduction towards optimum strategy. The criteria of "optimum" here is based on the cost-benefit consideration.

\section{RESOURCES ALLOCATION}

Resources are never unlimited. As mentioned earlier in Section 1, this study tries to develop a framework which result a more balanced strategy in flood risk reduction by accommodating idea of positive perspective upon flood's potential impacts. It is expected that the strategy might consist of a single or combination among various measures, both structural and non-structural ones. Consequently, the limited available resources need to be optimally allocated among the measures in order to result the minimum flood risk. Another study will specifically deal with this resources allocation which applying the concept of "comparative risk assessment" mentioned in Section 3. Furthermore, it is also a challenge to evaluate the effectiveness of implementation of certain flood risk reduction strategy [3].

\section{HISTORIC CASES ON FLOOD RISK REDUCTION}

The past studies aiming for flood risk reduction are categorized into several points as elaborated for review below.

\subsection{Balance vision between the losses and the benefits}

A study by Penning-Rowsell and Pardoe [9] demonstrated the benefit of flood by showing that flood risk reduction did not only bring benefits, but also losses for different parties. It disclosed that in addition to benefited parties ("gainers") such as owners of property with flood risk well as insurance companies and their shareholders, there were also the "losers", i.e. other taxpayer who are not related to any flood risk and people who rely on the work of flood damage repair or replacement. Further, Ferrier and Hague [10] stated that "flood risk management would provide a framework for balancing the multiple complementary and competing factors that affect risk. At the same time, a carefully crafted flood risk management strategy must also consider associated risks and opportunities, such as protecting natural floodplain functions from the detrimental impacts of human use."

\subsection{Balance management between the flood and its related aspects}

Ferrier and Hague [10] argued that flood risk management should be a more comprehensive approach then the old flood management of controlling the flood itself at various times and places. It must also cover the management of the

1. building and other development taking place in flood prone areas,

2. land area considered to be susceptible to flooding,

3. flood damage (with relief measures, insurance, and recovery assistance),

4. floodplain functions and resources (with regulatory controls or land management), and even

5. vulnerability of development (by applying site-specific mitigation measures).

A symposium conducted by the ASFPM Foundation [11] tried to identify the key benefits of a natural flooding process and the key resources provided by natural floodplains as well as the availability of models to prioritize or otherwise describe them. 


\subsection{Improved flood risk analysis}

Out of several definition upon "risk", this study opts to define flood risk as the product between probability of occurrence and its consequence of a flood event. Hence, the two main components in the analysis is the hazard and consequences.

\subsubsection{More accurate flood hazard analysis}

Hazard is not risk although they are interrelated and one is part of the other [10, 12]. Flood hazard analysis is the first part of flood risk analysis. Ferrier and Haque [10] studied the environmental hazard identification using the current major tools, i.e. research, screening, monitoring, and diagnosis. Other than the frequency (or probability) of occurrence of a given flood, a number of issues must also be explored, e.g. the time of last event occurred and the corresponding mitigation measures. A number of different sources to address the issues are required such as experts (scientists and researchers), published materials (textbooks, journal articles, databases), historical records in the library and/or municipality, newspapers, long-time residents, all with different qualities to consider and differently treated.

\subsubsection{More comprehensive flood consequence analysis}

In addition to flood hazard analysis, flood consequences analysis is the second part to be conducted in the flood risk analysis. The "quantitative risk assessment" mentioned earlier in Section 3 will be the main method used in this part. The benefits of flooding are included in this component of the flood risk equation, such as agricultural soil nourishment and water sources recharge. On the other hand, the ASFPM [11] revealed that individual and household behaviors in dealing with a particular threat are not related to their understanding of the actual risk of such events and/or their consequences. Hence, it is not completely true that by having a better knowledge on flood risk, people would take action to avoid or reduce it and be safer. The further question then be how to promote compulsory collective behavior which certainly cannot be conducted individually. This kind of education can also be considered as another benefit of flooding in improving the people's quality of life by living in harmony with the surrounding both physical and non-physical, including social environments.

\subsection{Complementary soft engineering to hard engineering for flood risk reduction measures}

Having the fact that flood defense cannot be against all floods [13] or in other words recognizing the limits of structural flood defense [14-16], and witnessing that the extensive investment in flood control works does not decrease the flood occurrence nor damages [17], solution for flood risk reduction has moved from hard to soft engineering solution and nonstructural approaches [18]. It is more promising to meet the "demands of sustainable development, a more strategic, holistic and long-term approach" of flood risk management [19]. Hooijer et al. [3] concluded their study that "the most effective and sustainable reduction of flood risks could be achieved by reducing the potential damage (vulnerability) in flood-prone areas through adapted land use and spatial planning".

The introduction of more public and private involvement to the government's role and responsibility in "modern flood risk management" in Japan has become more common practice in some other countries as well [16], e.g. Germany [20] and Vietnam [21] despite a 
higher level of heterogeneity in terms of Willingness to Pay (WTP) preferences of the latter as a developing country.

\section{CHALLENGES FOR FRAMEWORK IMPLEMENTATION: FROM VISION TO MISSION}

Taking into account most of the lesson learnt elaborated in Section 6, limiting the scope of this study to only flood risk assessment technical aspect shown in Figure 1a, potentially challenge the implementation of the proposed framework in terms of the following points. First, the United Kingdom with its Making Space for Water (MSW) undergoes the question of how the vision can be turned into mission (i.e. "policy prescription" [18]). In order to achieve successful implementation, the incorporation of the corresponding "legislative, financial, cultural, organizational, and social changes" aspects is significant. The second challenge is related to the stakeholders' (e.g. lay people's) perception [22] and "preferences for risk assessment indicators and assessment deliverables" [23], public participation [24] in decision making process [25] instead of "technocratic approach" [26], as well as policy of differing conceptual approaches to risk $[27,28]$. Those two points imply the necessity to see to what extent the flood risk assessment framework can be implemented in a scope isolation of this study.

\section{CONCLUSION}

Sharing a common understanding upon terminologies and having a same perspective in discussing the flood risk and its assessment are important to "address definitional and conceptual ambiguities". From that departure point, some countries have shifted their paradigm from "keeping flood water out", i.e. "flood fighting", to "flood defense", and finally "flood risk management", e.g. the United Kingdom, the Netherlands, and Germany. The latest concept strives for balance inclusion between managing the loss and benefit of flood event. Taking the defined "flood risk" as the function of the probability occurrence of a flood event and its consequences, those two sides of the coin are accommodated in the proposed framework of this study, specifically in their quantifications of the consequences analysis phase. For the reason of scope limitation, the framework is isolated only in the flood risk assessment as the core part of the whole flood risk management process. However, it is well understood that the non-technical aspects of "communication and consultation" as well as "monitoring and review" cannot be fully separated. It implies the necessity of anticipating its impact on the implementation results. In addition, the effectiveness of the resources allocation as the purpose of the framework needs to be measured, e.g. in a way represented by the effectiveness of the selected flood risk reduction strategy as the output of the framework implementation.

This study is a part of the doctoral research conducted by the corresponding author and sponsored by the Directorate General of Resources of Science, Technology, and Higher Education, Ministry of Research, Technology, and Higher Education.

\section{References}

1. P. Kungwani, IOSR J. Bus. Manag. Ver. III 16, 83 (2014)

2. ISO31000, Risk Management - Principles and Guidelines, First Edit (International Standard Organization, Geneva, Switzerland, 2009)

3. A. Hooijer, F. Klijn, G.B.M. Pedroli, and A.G. van Os, River Res. Appl. 20, 343 (2004) 
4. Business Dictionary.com (2017)

5. D. Crichton, Nat. Disaster Manag., 102 (1999)

6. P. Samuels, F. Klijn, and J. Dijkman, Irrig. Drain. 55, S141 (2006)

7. S.N. Jonkman, Loss of Life Estimation in Flood Risk Assessment - Theory and Applications (2007)

8. S. Gerrard and J. Petts, in Risk Assess. Risk Manag., edited by R.E. Hester and R.M. Harrison, 1-20 (The Royal Society of Chemistry, Cambridge, UK, 1998)

9. E.C. Penning-Rowsell and J. Pardoe, Environ. Plan. C Gov. Policy 30, 448 (2012)

10. N. Ferrier and C.E. Haque, Nat. Hazards 28, 271 (2003)

11. ASFPM, 1 (2009)

12. B. D. W. Davis and D. F. Munger, 1 (2014)

13. J. Bourn, Inland Flood Defence (London, 2001)

14. C. Johnson, E.C. Penning-Rowsell, and D. Parker, Geogr. J. 173, 374 (2007)

15. C. Johnson, E.C. Penning-Rowsell, and S. Tapsell, Area 39, 214 (2007)

16. G. Zhai, T. Sato, T. Fukuzono, S. Ikeda, and K. Yoshida, J. Am. Water Resour. Assoc. 42, 927 (2006)

17. Z.W. Kundzewicz and K. Takeuchi, Hydrol. Sci. J. 44, 417 (1999)

18. C.L. Johnson and S.J. Priest, Water Resour. Dev. 24, 513 (2008)

19. DEFRA, Making Space for Water - Developing a New Government Strategy for Flood and Coastal Erosion Risk Management in England (London, 2004)

20. D. Osberghaus, The Determinants of Private Flood Mitigation Measures in Germany Evidence from a Nationwide Survey (Mannheim, 2014)

21. A. Reynaud and M.H. Nguyen, Environ. Model. Assess. 21, 603 (2016)

22. R. Raaijmakers, J. Krywkow, and A. van der Veen, Nat. Hazards 46, 307 (2008)

23. S. Scheuer, D. Haase, and V. Meyer, Comput. Environ. Urban Syst. 37, 82 (2013)

24. L.S. Matott, J.E. Babendreier, and S.T. Purucker, Water Resour. Res. 45 (2009)

25. W. Kenyon, Ecol. Econ. 64, 70 (2007)

26. J.D. Brown and S.L. Damery, Trans. Inst. Br. Geogr. 27, 412 (2002)

27. C. Butler and N. Pidgeon, Environ. Plan. C Gov. Policy 29, 533 (2011)

28. J.A. Bradbury, Sci. Technol. Hum. Values 14, 380 (1989) 